MATEC Web of Conferences 40, 08002 (2016)

DOI: $10.1051 /$ matecconf $/ 20164008002$

(C) Owned by the authors, published by EDP Sciences, 2016

\title{
Controls of Hydraulic Wind Turbine
}

\author{
Yin Zhang ${ }^{1,2}$, Xiangdong Kong ${ }^{1}$, Li Hao ${ }^{1}$, Chao $\mathrm{Ai}^{1}$ \\ ${ }^{1}$ College of Mechanical Engineering Yanshan University, Qinhuangdao China \\ ${ }^{2}$ Qinhuangdao Institute of Technology, Qinhuangdao China
}

\begin{abstract}
In this paper a hydraulic wind turbine generator system was proposed based on analysis the current wind turbines technologies. The construction and principles were introduced. The mathematical model was verified using MATLAB and AMsim. A displacement closed loop of swash plate of motor and a speed closed loop of generator were setup, a PID control is introduced to maintain a constant speed and fixed frequency at wind turbine generator. Simulation and experiment demonstrated that the system can connect grid to generate electric and enhance reliability. The control system demonstrates a high performance speed regulation and effectiveness. The results are great significant to design a new type hydraulic wind turbine system.
\end{abstract}

\section{Introduction}

Following energy was consumed greatly; energy crisis and environment crisis were obvious (1). Wind energy is considered one of the most important green energies being developed and applied worldwide $(2,3)$. The utilization of wind energy as an alternative for fossil fuels is considerably growing due to an increasing environmental concern and exhaustion of fossil fuels (4, 5and 6). Modern large wind turbines can be classified into three different types, including the constant speed type, variable pitch control type and variable speed type. A variety of techniques are considered to transfer the wind energy to the power generator, including the application of gearboxes as well as gearless power transmission methods such as application of wind driven hydraulic devices. In recent years, hydraulic wind power harvesting systems are highly considered as a replacement to the conventional methods of generating electricity. In this method, wind turbines are employed to transfer the energy of the flowing air to electricity. A new concept, transferring the power via a hydraulic drive train is supposed to combine good efficiency and grid stability with high reliability and low costs $(7,8)$.

In non-direct driven wind turbine system gear-box was employed to transfer energy. But because the blades were connected to generator through gear-box rigidly, when the fluctuation of wind speed is great, the gear-box will be endure great lash and abrasion, then the life will be shorten, and manufacturing requirement of gear-box is strict, the delivery time is long, the universal property is bad because gear-box is suitable for special-type wind turbine. So the direct driven wind turbine is attended. In the direct driven wind turbine system, gear-box was removed, the blades coupled with generator directly, and then generator connected with grid through rectifier and inverter. But vane run slowly, so the electrodes of generator are more, and the capacity of generator is bigger, the weight is heavier, and the size is bigger. The control method is complicated. $(9,10)$.

This paper introduces the construction and principle of the hydraulic wind energy harvesting system. The system is different from other wind turbine in which closed hydraulic system with fixed displacement pump and variable displacement motor is proposed, generator connect with grid directly. So the control method and control variables or parameters are different from gearbox type and direct driven type wind turbine. In this system the angle of swash plate is controlled to keep the speed of generator constant to connect with grid. Simulation and experiment demonstrated that control method is validated. The results are great significant to design a new type hydraulic wind turbine system.

\section{Modelling of hydraulic wind turbine system}

The hydraulic wind power transfer system mainly consists of a fixed displacement pump driven by the wind turbine and a variable displacement motor which is controlled by servo variable cylinder. The hydraulic transmission uses the hydraulic pump to convert the mechanical input energy into pressurized fluid. Hydraulic hoses and steel pipes are used to transfer the harvested energy to the hydraulic motor, motor drives the generator to connect with grid.

A schematic diagram of the wind energy hydraulic transmission system is illustrated in Figure 1. 


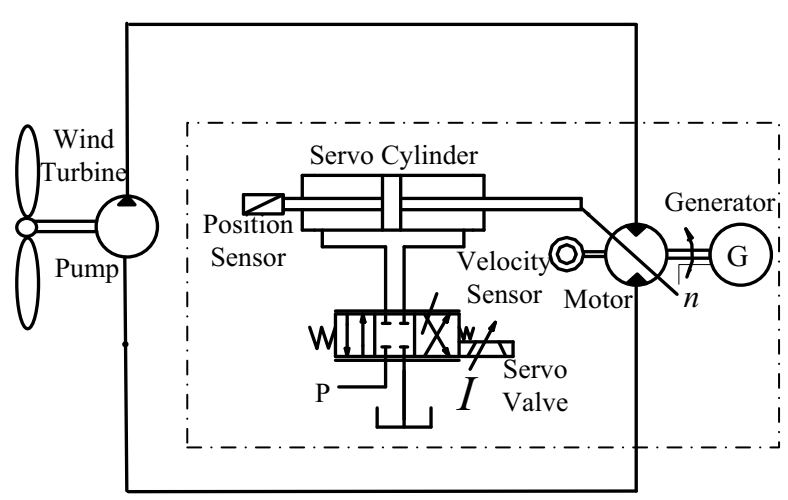

Figure 1. Schematic of the hydraulic system

In this hydraulic wind energy harvesting system, the generator transfers electric power to the grid with the constant angular velocity of motor. Moreover because of the intermittent nature of wind speed, the fluctuation of pump results in the speed wave of motor. The servo cylinder is required to change the displacement of swash plate of motor to adjust the flow for constant angular velocity. According to the signal of position sensor, a position closed loop control is applied to satisfy the requirement of variable displacement motor. According to the signal of velocity sensor, a velocity closed loop control is applied to satisfy the requirement of constant speed of motor.

The dynamic model of the hydraulic system is obtained by using governing equations of the hydraulic components in an integrated configuration. The governing equations of hydraulic motor and pump to calculate flow and torque are utilized to express the closed loop hydraulic system behavior $(17,18)$.

A. Fixed displacement pump:

The pump flow equation:

$Q_{p}=D_{p} \omega_{p}-C_{t p} P_{h}$

where is the pump flow delivery, is the pump displacement, is the pump angular velocity, is the pump leakage coefficient, and is the differential pressure across the pump.

B. Variable displacement motor:

The motor flow equation:

$$
\mathrm{Q}_{\mathrm{m}}=\mathrm{C}_{\mathrm{tm}} \mathrm{P}_{\mathrm{h}}+\mathrm{D}_{\mathrm{m} 0} \mathrm{X} \omega_{\mathrm{m}}+\frac{\mathrm{V}_{0}}{\beta} \frac{\mathrm{dP}_{\mathrm{h}}}{\mathrm{dt}}
$$

where is the motor flow delivery, is the motor leakage coefficient, is the motor maxium displacement, $\mathrm{X}$ is the motor displacement ratio, is the motor angular velocity, is the chamber volume of motor, is the fluid bulk modulus.

The motor torque equation:

$D_{m}\left(P_{h}-P_{s}\right)=D_{m 0} X\left(P_{h}-P_{s}\right)=B_{m} \omega_{m}+G \theta_{m}+T_{L}+J_{m} \frac{d \omega_{m}}{d t}$

where is the motor displacement, is the system pressure, is the motor kiematic viscosity coefficient, $G$ is the load stiffness coefficient, is the motor angular, is the load torque, is the motor enertia.

C. Servo valve
The servo valve flow equation:

$$
\mathrm{Q}_{\mathrm{L}}=\mathrm{K}_{\mathrm{q}} \mathrm{X}_{\mathrm{v}}=\frac{\mathrm{Q}_{1}+\mathrm{Q}_{2}}{2}
$$

where is the load of valve flow, is the valve flow coefficient, is the valve displacement, , is the different tunnel flow of valve respectly.

D. Cylinder

The cylinder flow equation:

$$
Q_{L}=A_{p} \frac{d X_{p}}{d t}+C_{t p} P_{L}+\frac{V_{t}}{4 \beta} \frac{d P_{L}}{d t}
$$

where is the load of cylinder flow, is the piston area, is the piston displacement, is the cylinder leakage coefficient, is the load pressure, , is the cylinder volume, is the fluid bulk modulus.

The cylinder force equation:

$$
A_{P} P_{L}=m_{t} \frac{d^{2} x_{p}}{d t^{2}}+B_{p} \frac{d x_{p}}{d t}+K_{P}+F_{L}
$$

where is the mass of load and cylinder, is the cylinder kinematic viscosity, $\mathrm{K}$ is the load stiffness coefficient, is the load force.

The overall hydraulic system can be connected as modules to represent the dynamic behavior. Block diagrams of the wind energy transfer using AMESim are demonstrated in Figure 2. The model incorporates the mathematical governing equations of individual hydraulic circuit component. The simulation model system includes closed loop of valve control-cylinder and closed loop of speed control.

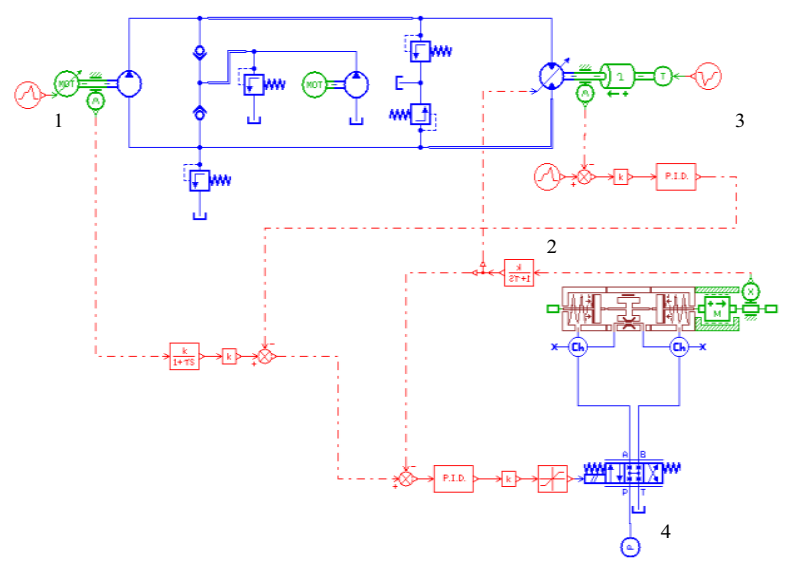

Figure 2. model schematic diagram of AMSim

Table I shows the simulation parameters for simulation models.

TABLE I SIMUATION PARAMETERS

\begin{tabular}{c|c}
\hline Pump displacement & $63 \mathrm{~cm}^{3} / \mathrm{r}$ \\
\hline Speed range of pump & $100 \mathrm{r} / \mathrm{min} \sim 900 \mathrm{r} / \mathrm{min}$ \\
\hline Maxium displacement of motor & $40 \mathrm{~cm}^{3} / \mathrm{r}$ \\
\hline Relief pressure of low pressure tube & $1 \mathrm{MPa}$ \\
\hline Relief pressure of high pressure tube & $35 \mathrm{MPa}$ \\
\hline Repleshing oil pressure & $0.4 \sim 0.9 \mathrm{MPa}$ \\
\hline The flow of replenishing oil & $100 \mathrm{~L} / \mathrm{min}$ \\
\hline Set speed of motor & $1500 \mathrm{r} / \mathrm{min}$ \\
\hline Enertia load & $1 \mathrm{~kg}^{*} \mathrm{~m}^{2}$ \\
\hline
\end{tabular}




\section{Controller design}

Model based on control system is designed to avoid the speed fluctuation of the hydraulic motor-generator with input variation. In order to regulate the speed, displacement closed loop of swash plate of motor and speed closed loop of motor is design. In this paper PID control strategy is used.

The control law to regulate speed of the hydraulic motor is given as

$$
C(\mathrm{~S})=\mathrm{K}_{\mathrm{p}}+\frac{K_{\mathrm{i}}}{\mathrm{S}}+\mathrm{K}_{\mathrm{d}} S
$$

Where $\mathrm{K}_{\mathrm{p}}$ is the proportional gain and $K_{\mathrm{i}}$ is the integrator gain and $\mathrm{K}_{\mathrm{d}}$ is the diffrential gain that can be adjusted to achieve a fast and accurate speed regulation. Figure 3 shows the control system configuration with PID controller. The control parameters can be adjusted to achieve the required performance.

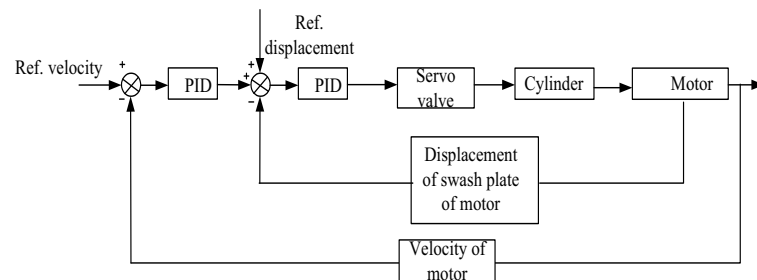

Figure 3. Control Configuration

\section{Simulation and discussion}

In order to prove the controller can be applied for hydraulic wind energy harvesting system, the motor dynamic velocity profile and system pressure were simulated and experimented.

In this case speed step signal of motor is set from 1485 $\mathrm{rpm} / \mathrm{s} 1500 \mathrm{rpm} / \mathrm{s}$. The Fig 4 is the simulaiton curves of motor speed and displacement of swash plate. The figure dipicted that the curve reach $1500 \mathrm{rpm} / \mathrm{s}$ after about 5 seconds, system is in the steady state. The displacement of swash plate is about 0.412 . Fig 5 is the simulation curves of system pressure. The high pressure is about 23.2bar, the low pressure is about 20.8bar. Fig 6 is the experemented response cureves of motor speed and displacement of swash plate.afer 5 seconds the speed of motor is about $1497 \mathrm{rpm} / \mathrm{s}$. The displacement of swash plate is about 0.401 . It can satisfy the requirement of sytem and can connect the grid to supply electric. When the step signal is set, the swash plate of motor was adjusting to change the flow of system to keep the speed of motor at $1500 \mathrm{rpm} / \mathrm{s}$. The pressure figure showed when the system is working, the pressure is stable.
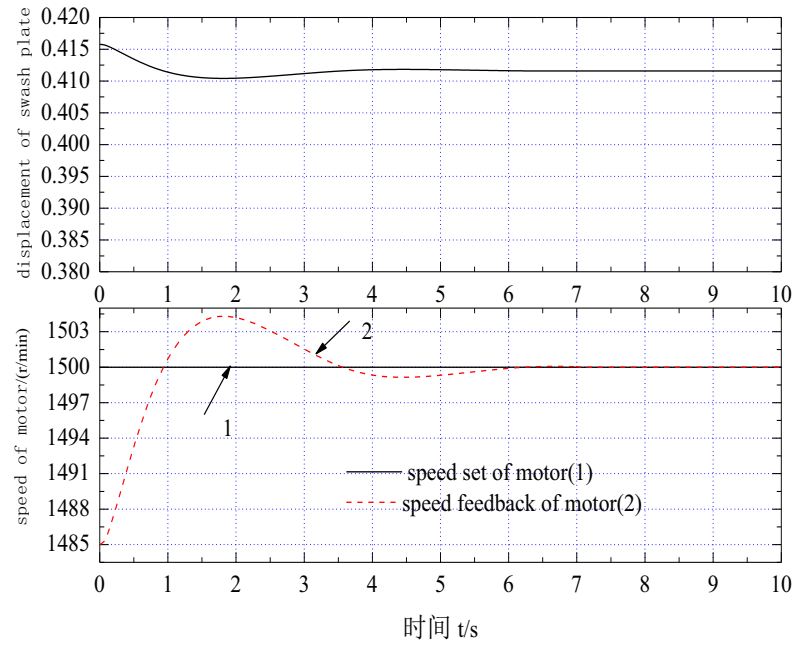

Figure 4. Simulation curves of motor speed and displacement of swash plate

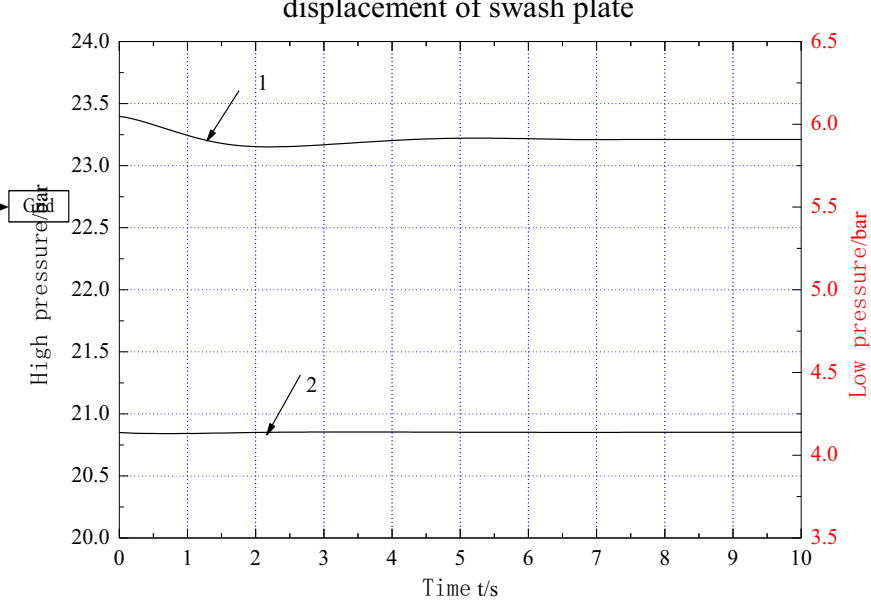

Figure 5. Simulation curves of pressure
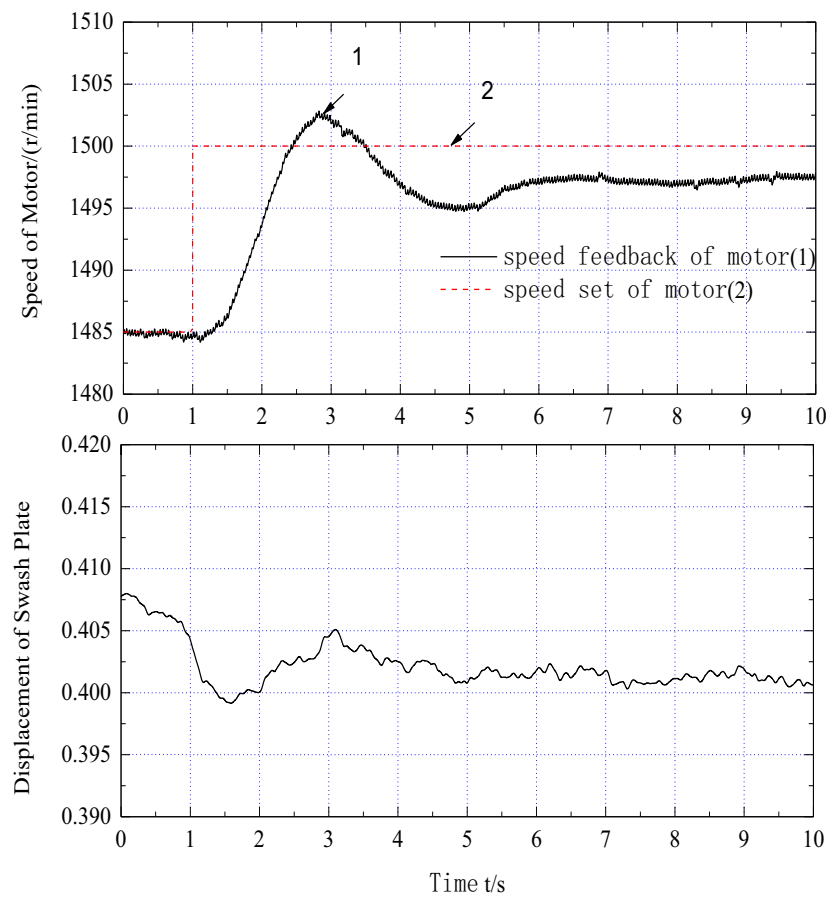

Figure 6. Response curves of motor speed and displacement of swash plate 

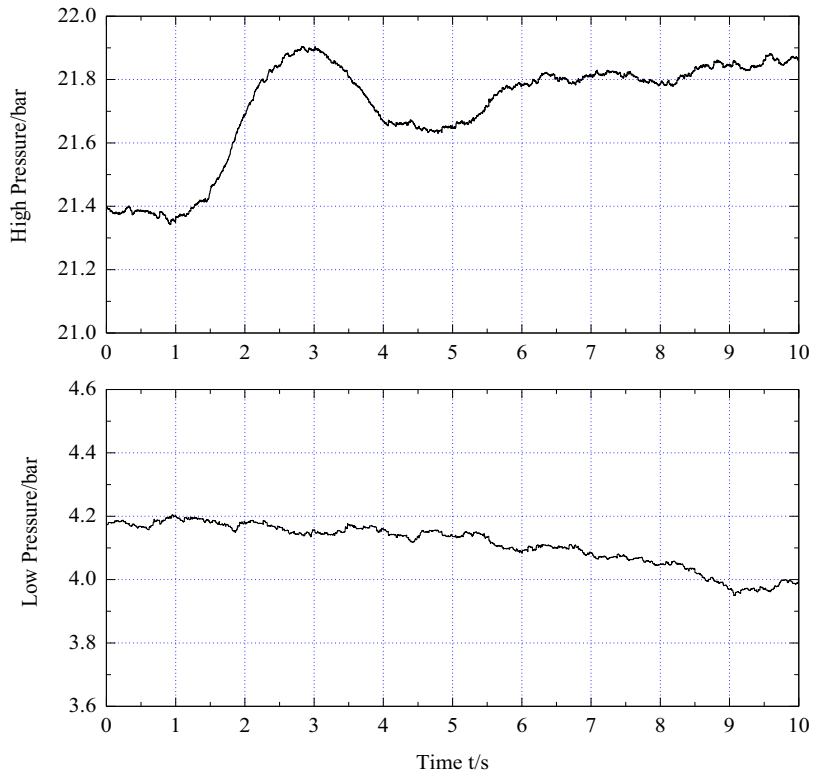

Figure 7. Response curves of pressure

\section{Conclusion}

This paper introduced a control strategy for a hydraulic wind energy transfer system. A mathematical model of the hydraulic model was created with MATLAB/Simulink and AMESim and governing equations. A displacement closed loop of swash plate of motor and a speed closed loop of generator were setup, a PID control technique is introduced to maintain a constant speed and fixed frequency at wind turbine generator. Simulation and experiment demonstrated that the system can connect grid to generate electric and enhance reliability. The control system demonstrates a high performance speed regulation and effectiveness.

\section{Acknowledgement}

This project is supported by National Natural Science Foundation of China (Grant No. 51375422) and The Education Department of Hebei Province (Grant No. QN20132017)

\section{References}

1. Fadaeinedjad, Roohollah, Moschopoulos, Gerry, Moallem, Mehrdad , "A New Wind Power Plant Simulation Method to Study Power Quality". 2007 Canadian Conference on Electrical and Computer Engineering, p 1433-6, 2007.

2. Chiang $\mathrm{M}-\mathrm{H}$. "A Novel Pitch Control System for a Wind Turbine Driven by A Variable-Speed PumpControlled Hydraulic Servo System". Mechatronics (2011),

3. T.Senjyu, R. Sakamoto, N. Urasaki, H. Higa, K. Uezato, and T. Funabashi, "Output Power Control of Wind Turbine Generator by Pitch Angle Control Using Minimum Variance Control," Electrical Engineering in Japan, vol. 154, no.2, 2006

4. J. G. Slootweg, H. Polinder, and W. L.King'Dynamic Modeling of a Wind Turbine with
Double Fed Induction Generator," IEEE Power Engineering Society Summer Meeting, 2001

5. Guo, Peng Bai, Nan, "Wind turbine gearbox condition monitoring with AAKR and moving window statistic methods". Energies, v 4, n 11, p 2077-2093, November 2011

6. Hamzehlouia, S. Izadian, A. "Modeling of Hydraulic Wind Power Transfers". 2012 IEEE Power and Energy Conference at Illinois (PECI), p 6 pp., 2012

7. R. M. Kamel, A. Chaouachi and K. Nagasaka, "Wind power smoothing using fuzzy logic pitch controller and energy capacitor system for improvement MicroGrid performance in islanding mode," Energy, vol.35, no. 5, pp. 2119-2129, 2010.

8. A. Ragheb, and M. Ragheb, "Wind Turbine Gearbox Technologies,"Proceedings of the 1st International Nuclear and Renewable EnergyConference (INRECIO), Amman, Jordan, March 2010.

9. A. Pusha, A. Izadian, S. Harnzehlouia, N. Girrens, and S. Anwar,"Modeling of Gearless Wind Power Transfer," IECON 20 II.

10. Y. Hou, 1. Li, P. He, Y. Zhang, and 1. Chen, "Shock AbsorberModeling and Simulation Based on Modelica," Proceedings of the 8thInternational Modelica Conference, issue 063, pp. 843-846, MF. De Lillo, F. Cecconi, G. Lacorata, A. Vulpiani, EPL, 84 (2008) 